\title{
COMMENTARY
}

\section{Free haemoglobin in 'old' transfused blood - baddy or bystander?}

\author{
Simon J Finney* \\ See related research by Vermeulen Windsant et al., http://ccforum.com/content/16/3/R95
}

\begin{abstract}
In the previous issue of Critical Care, Vermeulen Windsant and colleagues demonstrate that transfusion of packed red cells is associated with a transient increase in plasma free haemoglobin and scavenging of nitric oxide in vitro. They also demonstrate that older units of blood have more free haemoglobin in their supernatants. Whether the administration of older stored blood results in adverse clinical outcomes is a topical clinical question. The present study proposes a mechanism for transfusion-related harm but also has implications for patients who have other sources of free haemoglobin in their circulation.
\end{abstract}

In the previous issue of Critical Care, Vermeulen Windsant and colleagues demonstrate that transfusion of packed red cells is associated with a transient increase in plasma free haemoglobin and scavenging of nitric oxide (NO) in vitro [1]. They also demonstrate that older units of blood have more free haemoglobin in their supernatants. The implication is that the possible but unproven adverse effects of older transfused blood may be due to the inadvertent administration of free haemoglobin, enhanced NO scavenging, and modified microvascular flow.

However, it is still unclear whether allogenic blood stored for longer periods of time has adverse effects for the recipient. Observational data demonstrate that the use of older blood in patients who have undergone cardiac surgery is associated with an increased mortality [2]. By contrast, others have demonstrated variable effects on physiological indices that are surrogates for organ perfusion $[3,4]$. These contrasting data and widespread equipoise from clinicians have fuelled several

*Correspondence: s.finney@imperial.ac.uk

Adult Intensive Care Unit, Royal Brompton Hospital, Sydney Street, London SW3 6NP, UK clinical trials: the Age of Blood Evaluation Study (ISCRTN 44878718), the Red Cell Storage Duration Study (NCT00991341), and Red Cell Storage Duration and Outcomes in Cardiac Surgery (NCT00458783). These studies differ in their control groups and patient populations, with the first recruiting a wide group of critically ill patients and the latter two just examining those that have undergone cardiac surgery. Undoubtedly, the results of these studies will be of great interest to clinicians. The implications for the blood transfusion services, who typically issue the oldest blood to conserve precious and limited stocks, are immense.

The limitation of the present study is that only one mechanism of many is investigated and the link to adverse outcomes in patients is not considered [5,6]. Indeed, it is possible that several mechanisms exist, such as the administration of older more fragile erythrocytes, depletion of adenosine triphosphate and 2,3-diphosphoglycerate, or the presence of cytokines, histamine, and complement in supernatants. Furthermore, free haemoglobin has other effects such as renal tubular toxicity and decompartmentalisation of iron, which may influence the redox balance, microbial killing, or intracellular signalling [7]. Finally, NO has roles other than that as mediator of vascular tone. Free haemoglobin and NO scavenging may thus be events that occur in parallel with other phenomena. Nevertheless, nonselective inhibition of the NO pathway has been associated with increased mortality in sepsis [8] and the authors describe a very plausible mechanism. The physiological and biochemical readout from the aforementioned clinical trials will be key in our understanding and the current study will inform such analyses.

Important also is the authors' observation that higher pre-transfusion haptoglobin levels appear to be protective in terms of a rise in free haemoglobin and NO scavenging. The implication is that the administration of haptoglobin may mitigate against any adverse effects of free haemoglobin, particularly in the setting of significant haemorrhage and cardiac surgery when levels are likely to be low. This is supported by the fact that free haemoglobin appears to stay primarily in the blood compartment in 
conjunction with any administered haptoglobin. Quantitatively, the rise in plasma free haemoglobin following a 2-unit transfusion suggests that the free haemoglobin administered is diluted about 13 -fold and that the volume of distribution is of the order of $7 \mathrm{l}$, similar to an adult's total blood volume. Haemolysis may also be a significant contributor to organ dysfunction in other scenarios encountered in the critically ill: haemoglobinopathies, severe infection (for example, malaria, Escherichia coli), cardiac valvular disease, and the use of extracorporeal therapies such as renal replacement therapy, cardiopulmonary bypass, and extracorporeal membrane oxygenation.

Mechanisms are important. Clinicians often need to understand the rationale prior to changing practice. This study generates the hypothesis that free haemoglobin present in older blood may be detrimental by modulating the NO pathway, which merits consideration when clinical trials are evaluated.

\section{Abbreviations}

NO, nitric oxide.

\section{Competing interests}

The author declares that he has no competing interests.

Published: 31 July 2012

\section{References}

1. Vermeulen Windsant IL, de Wit NCJ, Sertorio JTC, Beckers EAM, Tanus-Santos JE, Jacobs MJ, Buurman WA: Blood transfusions increase circulating plasma free hemoglobin levels and plasma nitric oxide consumption: a prospective observational study. Crit Care 2012, 16:R95.

2. Koch CG, Li L, Sessler DI, Figueroa P, Hoeltge GA, Mihaljevic T, Blackstone EH: Duration of red-cell storage and complications after cardiac surgery. $N$ Engl J Med 2008, 358:1229-1239.

3. Marik PE, Sibbald WJ: Effect of stored-blood transfusion on oxygen delivery in patients with sepsis. JAMA 1993, 269:3024-3029.

4. Walsh TS, McArdle F, McLellan SA, Maciver C, Maginnis M, Prescott RJ, McClelland DB: Does the storage time of transfused red blood cells influence regional or global indexes of tissue oxygenation in anemic critically ill patients? Crit Care Med 2004, 32:364-371.

5. Zimrin AB, Hess JR: Current issues relating to the transfusion of stored red blood cells. Vox Sang 2009, 96:93-103.

6. Tinmouth A, Fergusson D, Yee IC, Hebert PC: Clinical consequences of red cell storage in the critically ill. Transfusion 2006, 46:2014-2027.

7. Lagan AL, Melley DD, Evans TW, Quinlan GJ: Pathogenesis of the systemic inflammatory syndrome and acute lung injury: role of iron mobilization and decompartmentalization. Am J Physiol Lung Cell Mol Physiol 2008, 294:L161-L174.

8. López A, Lorente JA, Steingrub J, Bakker J, McLuckie A, Willatts S, Brockway M, Anzueto A, Holzapfel L, Breen D, Silverman MS, Takala J, Donaldson J, Arneson C, Grove G, Grossman S, Grover R: Multiple-center, randomized, placebocontrolled, double-blind study of the nitric oxide synthase inhibitor 546C88: effect on survival in patients with septic shock. Crit Care Med 2004, 32:21-30.

doi:10.1186/cc11411

Cite this article as: Finney SJ: Free haemoglobin in 'old' transfused blood baddy or bystander? Critical Care 2012, 16:141. 